\section{Examining the progression of mobile technologies and their applications to learning environment: Implications for m-learning in Africa}

\author{
Dankasa, Jacob $\bowtie$ \\ University of North Texas, Denton, USA (jdankasa@gmail.com)
}

Received: 30 May 2014

Available Online: 20 June 2014
Revised: 18 June 2014 DOI: $10.5861 /$ ijrset.2014.825

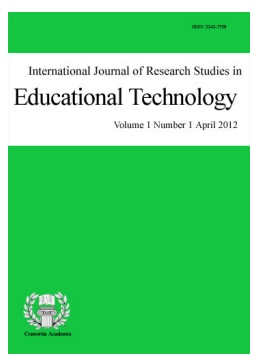

ISSN: $2243-7738$ Online ISSN: 2243-7746

OPEN ACCESS

\title{
Abstract
}

Mobile technologies are promising features that point to the future of instruction and learning. This paper reviews literature on mobile technology in order to identify areas of focus for researchers with interest in Africa towards contextualizing the use of mobile technology for mobile learning (m-learning) within the African experience. It examined the uses of mobile technologies as explored by researchers and pointed out the benefits and drawbacks. This paper extracted the recommendations of researchers on how to overcome or correct the setbacks to the implementation of mobile technology into the learning environment. It recommended offline access to learning materials on mobile devices to be seriously contemplated for m-learning in Africa. There is need for further research in the developing world of Africa to measure the outcome of offline mobile learning and its effects on cost reduction, and to develop theoretical frameworks that will evaluate programs, learners and instructors for building effective instructional design using the mobile technologies. This paper draws a roadmap and sets the ball rolling for designers of mobile learning modules, instructors and researchers in the field of education to work in situating learning with mobile technology as a method of choice in the learning environment. It also demonstrates to learners the much functionality their mobile devices offer them in attaining their educational goals.

Keywords: mobile learning; mobile devices; mobile education; ubiquitous learning; instructional design 


\section{Examining the progression of mobile technologies and their applications to learning environment: Implications for m-learning in Africa}

\section{Introduction}

The use of mobile technologies for instruction and learning is still in its developmental phase, but the growth of these technologies has reached a level that we cannot ignore. Many use mobile devices for variety of reasons. Whatever reason one uses these devices, the reality is that it is a widespread phenomenon. The Pew research reported that $92 \%$ of undergraduates and $88 \%$ of graduate students in America own a wireless device; and $98 \%$ of undergraduates and $99 \%$ of graduate students are Internet users (Rainie, 2011). On a global level, about $96 \%$ of the world's population (6.8 billion people) was mobile subscribers by the end of 2012. This is in terms of phone SIM cards in use (Global Mobile Statistics, 2014). Africa is a hub for mobile technology. The growth in the use of mobile devices, such as the mobile phone, is astronomical; an estimated $63.5 \%$ of Africans are mobile subscribers in 2013. This is up from 12.4\% in 2005 (ITU, 2013), and increasing number of people in Africa than in other regions of the world view web pages on mobile devices by May 2014 (Meeker, 2014)

The mobile technologies are promising features that point to the future of instruction and learning. The field of m-learning is new and growing but changing at different phases because of the dynamism of technology. M-learning, which stands for mobile learning, is a type of learning that cuts across different contexts using electronic devices for content and social interactions (Crompton, 2014). As technologies come and go users struggle to adjust to innovations and changes in the application of different devices. Using technological devices requires some level of dexterity, knowledge and effectiveness. As we search for new pedagogy, we need to evaluate those tools that will serve as aids to knowledge acquisition and examine their potential impact on the learning environment.

The uses of the mobile technologies for m-learning are still experimental at different levels. In this early stage, researchers are examining the functionalities of the devices to explore their benefits to instruction and learning. Pask (cited in Motiwalla, 2007) pointed out that conversation theory suggests successful learning requires a continuous two-way conversation between the teacher and the learner and among learners. Based on this theory, Motiwalla (2007) concluded that mobile learning using the mobile technologies is capable of achieving the goal of the conversation theory. By implication, the mobile technologies are capable of bringing about successful learning.

While there is a growing number of studies in the western world to demonstrate the usefulness of mobile technology for learning, similar studies are lacking in the developing world of Africa. A study by Hwang and Tsai (2011) that reviewed the growth of research in mobile and ubiquitous learning based on articles published in Social Science Citation Index journals from 2001 to 2010, found only one article from a country of Africa. The data are lacking to make informed decisions on how to utilize effectively the growing use of technology among the Africans to translate it into modalities for enhancing learning and education. Brown (2005) envisioned a model for m-learning in Africa. However, with the offshoot of improved mobile technologies over time such as smartphones and tablets, such a model requires revision through wide range research. There is a dearth of experimental research in the area of mobile technology and its application to learning and education in the developing countries of Africa.

As a sign of progress, since the review of Hwang and Tsai (2011), a few studies have started to emerge from Africa on this area (Chang, et al., 2012; Lwoga, 2012; Johnson, 2013; Chambo, Nkansah-Gyekye, \& Ndume, 2013). Nevertheless, practical applications of these devices in research are still short. Winters (2013) advises that researchers on m-learning in the developing world need to look into the large body of research available on mobile learning in order to derive a model to follow in implementing the process in their education system. It is 
therefore very essential to utilize the experiences of the western world on the application of mobile technology in the learning environment to develop a caveat for researchers with interest in Africa to engage in groundbreaking studies. Such studies could align Africa with the rest of the world in developing methodological and practical means for effective implementation of the use of mobile technologies in the learning environment.

Based on this background, this paper reviews literature on mobile technology in order to achieve the following objectives.

$>\quad$ To identify the different types of mobile technologies that can enhance learning.

$>\quad$ To identify the strength and weaknesses of these mobile technologies as they relate to learning.

$>$ To explore appropriate steps to correct the potential setbacks of the mobile technologies and make them more fitting for learning.

$>\quad$ To identify areas of focus for researchers with interest in Africa towards contextualizing the use of mobile technology for m-learning within the African experience.

This review is of special relevance to designers of learning modules and instructors in mobile learning who will be involved in developing instructional curriculum and teaching in an academic environment that is fast changing. Researchers interested in developing a theoretical framework for this emerging area of learning will find this paper beneficial as it provokes thoughts about developing a new paradigm for education. This review will be relevant to researchers with interest in Africa and other developing nations of the world. A group that will also find this paper useful is the learners, who will be motivated by the many functionalities they will realize come out of their mobile devices.

\section{Methodology}

This paper relies heavily on the review of literature on mobile technology vis-à-vis mobile learning. The search process for the articles to be included in this review began in the fall of 2011 with a research project for a course on Computer Education and Cognitive Science. As at the time, only articles published in the previous 10 years were included in the final paper. Another search process was conducted in 2014 to revise the contents of the literature review. Hence, the paper that was previously prepared as a final project for an academic semester course was revised and updated with relevant current literature on the subject of mobile technologies for m-learning.

Several studies were retrieved from Google scholar and the electronic database of the University of North Texas, particularly the online articles and EBSCOhost. General search was conducted and different search terms were used to retrieve relevant articles. The search terms include mobile technology, mobile learning, mobile technology for education, uses of mobile technology for education, and studies on mobile technology in Africa. Studies published since 2005 were given priority because of the explosion of modern mobile technology devices within this period. However, a few studies from prior years were selected because of their relevance to the topic. About 250 articles were retrieved on the subject of mobile technology for m-learning. Scanning through the abstracts and methodology of the articles, I determined which study should be included in this review. Studies that experimented with the mobile technologies were preferred to mere surveys and interviews, except for one occasion where the study relates to Africa. A few literature reviews on mobile technology were included. Forty-one scholarly articles were selected for review. The selected studies were read in full.

\subsection{Data analysis}

The articles selected for review were carefully read in order to find those issues that address the main objectives of this paper. I examined the different studies to find the uses of mobile technologies as explored by researchers. I looked out for the benefits and drawbacks as put forward by the studies and extracted the 
recommendations of researchers on how to overcome or correct the setbacks to the implementation of the mobile technology into the learning environment. From these findings, I evaluated what they mean to the future of m-learning in Africa and suggested the directions for future research in this area.

\subsection{Limitations}

This paper will not claim to have consulted all relevant studies done on the subject of mobile technology for m-learning. The articles used for this review were all retrieved from online database, which are mostly journal articles. Printed materials such as books were not used. It is possible to obtain relevant materials on this topic from sources outside online database. However, the goal of this paper is to spur researchers into thinking of m-learning as an area that needs further attention for the growth of the African education system. It is not intended to be a comprehensive report of all research done on this subject. To this effect, the search for documents stopped when a reasonable case was perceived to be established with articles adjudged to address the objectives of the paper.

\section{Key Findings}

The findings of this review are presented based on the uses, the benefits and the drawbacks of the mobile technologies as presented by different research studies.

\subsection{Identifying mobile technologies and their uses}

Various studies have been carried out on the uses of mobile technologies and their impact on the learning environment (Aubusson, Schuck, \& Burden, 2009; Shen, Wang, Gao, Novak, \& Tang, 2009; Economides, \& Nikolaou, 2008; Alamaki, \& Seppala, 2002). By mobile technology, we refer to portable and personal devices such as portable gaming devices, Personal Digital Assistants (PDA), tablets and mobile phones, which are the technologies commonly used for mobile learning (Marwan, Madar, \& Fuad, 2013; Pegrum, Oakley, \& Faulkner, 2013; Kingston et al., 2012; Naismith, Lonsdale, Vavoula, \& Sharples, 2004 ).

Stav, Nielsen, Hansen-Nygard, and Thorseth (2010) presented a study on Student Response System (SRS) technology. SRS allows a teacher to ask a question and receive an answer through a response device. The aim of this was to support and improve communication and interactivity among teachers and students. The SRS allows the teacher to analyze the data collected from the students, using it to determine if learning takes place. In SRS, the instructor had a receiver with software installed in it and the students used a keypad. In this study, iPods, iPhones and other mobile devices were used as sample web-based SRS.

Ying, Lun, Zipf, and Kimm (2014) similarly tested the use of a prototype where the teacher lectured with his tablet while the students joined in the interaction using their personal devices that were all interconnected. This was intended to build a mobile learning program using the iOS platform. The teacher used an application called Teaching Instructor Application (TIApp), while the students used Student Instruction Application (SIApp). The applications were meant to help improve teacher-student communication especially in a larger classroom. Students who are shy to participate in large classroom will also use this opportunity to ask questions and contribute to the discussion in real time. Twenty-eight students took part in this experiment using the iPad. The study found that the SIApp increased students' motivation to participate in the lecture, helped them better understand the course content, enabled them to read lecture notes at any location and encouraged the giving of feedback to the teacher.

Similarly, the University of Twente in the Netherlands carried out a project called M-Poort. Courses of the university were made available through a WAP-enabled phone (WAP stands for wireless application protocol used in mobile phones to retrieve information) where students had their assignments and communicated with other students and teachers online (Kim, Mims, \& Holmes, 2006). In another study within the clinical setting, Clay (2011) used iPods for students to acquire some clinical skills. The results of this clinical experiment 
showed that the use of iPod is capable of enhancing learning because it brings about portability, immediacy, individuality, connectivity and accessibility. In a study carried out by Fisher and Baird (2007), instructors took polls and checked the understanding of the students using mobile phones. The study showed increase and ease of interactivity in a large classroom. Fisher and Baird contended that a method like this "focuses on what the student does, rather than on what the lecturer does" (p. 13). Hence, such use of mobile technology opens the student to a do-it-yourself approach to learning. In the same vein, they identified some emerging mobile technologies which included Buddy Buzz, "an application that allows users to quickly read text on a mobile phone using a variation of the rapid serial visual presentation (RSVP) interface" (p. 20). Users were able to read and understand text on the mobile phone.

A study by Coulby, Hennessey, Davies, and Fuller (2011) used the PDA with a group of final-year undergraduate medical students to examine its effect on delivering competency-based assessment. The results showed that using PDA for learning facilitates immediate feedback. Other mobile technologies used were the Play Station Portable (PSP) and Video iPod. The PSP is an integration of multiple functionalities with multimedia player, video, audio with an e-book reader, all in one, and WI-FI capability. The video iPod provides opportunity for teachers to share audio and video content with their students.

Motiwalla (2007) developed a mobile learning architecture by making applications available through any mobile device that supports Wireless Application Protocol (WAP). Motiwalla created an interactive forum where students and teachers used their wireless handheld devices to access course materials. They utilized open source software such as vBulletin and WiForum. The vBulletin application linked to the discussion forum through a PC and the participants used their WAP-enabled mobile phone devices for access with the help of the WiForum application.

Instant messaging through Short Message Service (SMS) is another approach used to test the workability of mobile technology in a learning situation (Lim, Fadzil, \& Mansor, 2011). Kingston University carried out an experiment to determine the suitability of SMS for two-way communication. Explaining this study, Trifonova (2003) mentioned that students registered into the service and provided information about themselves and their activities. The study separated the students into groups and sent messages to them through email, SMS and web. Different groups received messages by different methods. They found that some students preferred SMS to other forms of messaging used because the data were more personal to them. This study suggests SMS is a vital tool of the mobile technology and has potential impact in the mobile learning process. SMS with Multimedia Messaging Service (MMS) are the most common wireless phone applications used in teaching and learning because most mobile phones support them (Kim et al., 2006; Valk, Rashid, \& Elder, 2010).

In a recent study conducted in Africa, Pimmer, Brysiewicz, Linxen, Walters, Chipps, and Grohbiel (2014) explored how nurses in marginalized and remote areas used mobile phones as effective tools for education. The study conducted in South Africa interviewed 16 nurses. It found that the use of mobile phones encouraged reflective practice, enhanced authentic problem solving, facilitated life-long learning and presented the feeling of belonging and emotional support. They found the mobile phone to be the dominant tool used to access knowledge in this setting. They concluded that these devices help in connecting learners, especially in low-income and marginalized areas.

Chang et al. (2012) used smartphones in a study of resident physicians in Botswana to test the phones' effect on their specialty training. Some applications were installed into the smartphones, which included point of care and drug information with telemedicine applications that will allow students submit their cases to their assigned mentors. The included applications had drug references and resources that assist residents in making clinical decisions. They all had access to mail and web in the smartphones. Surveys were taken before giving them the phones to ascertain how familiar they were with smartphone technology. A Follow-up survey was administered a few weeks after the phone distributions. This was to assess if the applications were used, how frequently they were used, and how comfortable the physicians were with the devices. The study found that the resident 
physicians effectively utilized the applications in the smartphones both for self-directed learning at home and at patient rooms to access point-of-care medical information. In the same vein, Johnson (2013) tried to analyze the roles of mobile phones in qualitative inquiries at two public universities in Kenya. She concluded that the use of mobile phones has the ability of reducing the obstacles encountered during data collection. These studies showed the vital role of mobile phones in m-learning in Africa.

From the different studies carried out on the educational uses of the emerging mobile technologies, it is evident that the future of education for the next generation lies in this trend. Therefore, ascertaining the benefits of the mobile learning process will spur more thinking and research in this area.

\subsection{Benefits of mobile technology to learning}

Mobile technology has the potential to facilitate participation, collaboration, cognitive involvement and self-assessment during the learning process (Stav et al., 2010). This potential can be seen from the outcome of studies on the mobile technologies. The results of the study by Clay (2011) showed that mobile technology brings about immediacy, individuality, connectivity and accessibility that enhance mobile learning. Some students in the Stav et al. study reported that confidentiality was very important to them. Using the keypad of their mobile devices to submit answers instead of raising their hands made their individual responses stay confidential.

An important characteristic of the mobile technologies is their wireless capabilities. One great advantage that the wireless technologies have over the wired technologies is their ability to provide anytime, anywhere functionality, which minimizes the limitation of educational flexibility (Kim et al., 2006). Martin and Ertzberger (2013) tested the effect of here-and-now mobile learning using iPad and iPod on the attitudes of undergraduate students. They found the students to have positive attitudes towards the mobile technologies and to be motivated because of the here-and-now learning environment they were able to access, which they felt increased their interest to learn.

Kim et al. (2006) identified mobility and reachability as two basic characteristics of the mobile technologies that transcend the limitation of time and location. These create flexibility in time and place of learning by placing learning in the hands of the learner, hence increasing interest in the learning materials (Clay, 2011). The PDA, for instance, allows students and teachers to work at different places, and teachers to manage students' grades and lecture materials at anytime and anywhere. The beaming capabilities of the PDA could be used to send and receive documents, submit assignments, questions and quizzes, and to share files instantly (Kim et al., 2006). Using the PDA is straightforward; it increases and improves the level of feedback, which allows students improve their skills (Coulby et al., 2011).

Evidence from the study by Clay (2011) also shows that the iPod offers support for active learning in the area of clinical practice and provides exciting, innovative and creative means of learning and facilitation. This is same with the mobile phones, especially smartphones, which have come to be one of the mobile technologies that learners use most frequently. Norris and Soloway (2010) described the mobile phone as the "quintessential technology of today's mobile generation" (p. 51). The SMS, for instance, through the mobile phones, has facilitated an increase in students' knowledge (Valk et al., 2010). Oku (cited in Kim et al., 2006, p. 92) outlines the benefits of mobile wireless phones for teaching and learning thus:

$>\quad$ Provide students with freedom of location and time

$>\quad$ Increase speed in teaching and learning

$>\quad$ Enable one-to-one learning based on individual educational histories or test results

$>\quad$ Allow teachers to keep up with new educational developments for future use in their teaching. 
The learning space provided by mobile technology is capable of opening up the potential for maximum participation, increased motivation and increased peer feedback and collaboration during the learning process (Fisher \& Baid, 2007). There is a kind of active anytime/anywhere engagement that comes with mobile learning, where students receive alerts on their mobile devices when there is a new post on the discussion board. The devices become good complementary tools for classroom interaction (Motiwalla, 2007). They also serve as a constant reminder of the course for the students.

The flexibility that the mobile technologies offer lessens the weaknesses of coordination, communication, organization, negotiation, interactivity and mobility that are evident in learning without technology (Cobroft, Towers, Smith, \& Bruns, 2006), and by extension, reduces barriers to education (Valk et al., 2010). This shared conversation space that mobile technologies bring increases the conversational aspect of learning because it brings people to communicate and share with each other (Naismith et al., 2004). It is therefore not surprising that the collaboration and communication attributes of mobile devices stand at the highest point in the mobility hierarchy developed by Gay, Rieger, and Bennington (2002), which demonstrates the different stages of mobile technology application. It shows that mobile devices are communication intensive and are capable of increasing communication, group work and synchronous learning among students.

From the foregoing, the mobile technologies create a mobile learning environment that allows greater freedom of schedule, flexibility of modules, increased interaction and the capacity for immediate feedback. Notwithstanding these tremendous benefits of mobile technologies to the learning environment, the process has some setbacks that deserve attention.

\subsection{Potential drawbacks of mobile technology}

One of the problems of the mobile technologies is the cost (Conde, García-Peñalvo, Alier, \& Piguillem, 2013; Stav et al., 2010; Trifonova, \& Ronchetti, 2003). Most devices are expensive and the Internet service that enables the usage of sufficient data comes with a price. This may be a burden for the student and may lead to many not having access to efficient devices. Small screen size could also constitute a nuisance to the user (De Castro, 2014; Elias, 2011; Fisher \& Baird, 2007; Motiwalla, 2007; Keegan, 2002). Web pages in most cases are designed to fit on a desktop computer with larger screen size and higher resolution, but are compressed to fit the smaller devices. This makes the web pages "aesthetically unpleasant, unnavigable, and in the worst case, completely illegible" (Trifonova \& Ronchetti, 2003, p. 1795). Participants in the study of Motiwalla (2007) found the screen size to be a problem that made typing on the phone keypad a tedious process. The small screen will make it difficult for someone to take a two-hour course on a mobile phone. Kim et al. (2006), on the other hand, identified security issues and technology sophistication as major problems to proper implementation of this learning method.

A very important feature that the mobile technologies offer to education is the streaming media. However, with mobile devices there are the problems of connection speed, processing capabilities (Trifonova \& Ronchetti, 2003), and limited memory (Elias, 2011). This is in addition to the awkward slow response time, and lack of visual stimulation (Motiwalla, 2007).

Flexibility is seen as a major advantage that the mobile technologies bring with their anytime/anyplace capability. However, Motiwalla warned flexibility might result in unforeseen consequences for the learners. One such consequence is "the information and interaction overload. Anytime and anywhere connectivity may become 24/7 headaches, which may result in the danger of learners [sic] becoming chaotic" (p. 594).

In the study of Valk et al. (2010) that used mobile phones for SMS quizzes, the volume of incoming messages was a shortfall because it resulted to delays in the auto reply system. There was also a problem with the quizzes, which resulted from the students' entering wrong keywords. Valk et al. also found that the actual cost of using the SMS for the quizzes was more than that of other modes of learning used previously. They found that in developing countries of Asia, learning facilitated by mobile phones does not have impact on 
Dankasa, J.

educational outcome or promote new learning.

\section{Discussion}

Based on the findings of this review, this section discusses the implication of these findings to educational technology, especially to students, teachers and content developers, and its relevance and implications to education in Africa.

\subsection{Implications for instructors, learners and content developers}

This review reveals great prospects and challenges for the implementation of mobile technology into the instruction and learning process. One important positive side of mobile technology that keeps coming up in most studies consulted is its potential for enhancing learning. This review confirms and supports the view of Motiwalla (2007) that mobile technology has the potential for bringing about improved and increased conversation between teachers and students and among students. This is achieved through the flexibility and the anytime/anywhere functionality that mobile technology brings. For those students who are shy or cannot participate in a traditional classroom discussion, the confidentiality the mobile technology presents, as shown by Ying et al. (2014) in the TIApp/SIApp study and Stav et al. (2010) with the use of the SRS on mobile devices, allows such students to engage in discussion with others freely. This increases interactivity that promotes a two-way conversation, thereby enhancing learning. Considering the tremendous potential of the mobile technologies to facilitate successful learning, this seems to be the way to go in the future of education.

However, for mobile technology to play an effective role in the learning process some issues have to be resolved or at least improvements are needed. Some of the factors that several studies mentioned as obstacles to adequate implementation of the mobile technologies are the cost, small screen size and lower resolution, security issues and technology sophistication, connection speed, limited memory, and information and interaction overload. With development in technologies however, some of the shortfalls of the mobile devices are improved tremendously with better prospects for the future. We still cannot overlook some of the issues they pose if success is the goal. How do we work to translate the potential negativity of this new teaching approach into something positive for effective learning?

According to Stav et al., all instructional technologies should have learning as their sole goal because we improve the classroom when we link technology to modern day and give it an instructional purpose. Therefore, the use of mobile technology for learning has to take cognizance of the technology tools that students are already using. In this light, there is need for a change of style in the use of technology for instruction and learning, especially with the mobile technologies. Mobile technology is a new communication tool, and so new technical knowledge is necessary on the part of instructors and students (Gibbons, 2009).

Fisher and Baird (2007) stressed the need to design a student-centered learning environment. The instructor should use this learning environment to help students achieve optimum learning through enhanced collaboration between the teacher and the student. On the issue of the smaller screen of mobile devices that makes it difficult to read large amounts of documents, Fisher and Baird advised that those who design mobile learning "should keep in mind the constraints and limitations of the platform they are designing for and develop educational content with specific type of mobile device in mind" (p. 7). They offered the following suggestions to mobile learning designers: limit text-centric learning content, limit the number of actions required on the keypad, and include only contents that are most important or required for the mobile learning. They suggested there should be reversal of the educational model in order to conform to the learner, not make the learner conform to the system. In this case, the content, rather than the device, should be the subject of attention for m-learning curriculum designers.

The proper design of mobile learning is very important in order to achieve its goal of providing efficient access to educational services. Valk et al. (2010) suggested careful planning in this regard to ensure that effective 
design of mobile-phone-facilitated learning and its implementation do not suffer due to technological factors. On this topic, Fisher and Baird proposed three considerations for effective mobile learning design:

$>$ A user-experience design: the design should provide an engaging content that allows the learner to connect between the contexts of the learning and its objectives.

$>$ Interaction design: this has to do with integrating social software into the mobile learning environment. Here, the course designers must be careful not to burden the learner with too many content or software requirements; rather, the software should promote social interaction.

Mobile content design: this is where curriculum designers planning for mobile phones minimize the amount of text and make use of mobile text reading tools such as the Rapid Serial Visual Presentation (RSVP) to allow readers read more text.

Trifonova and Ronchetti (2003) offered more recommendations to the designers of m-learning that could serve as guidelines in curriculum design:

$>$ Modules should be short, lasting not more than 5 to 10 minutes. The little time users have should be good enough to read through small pieces of data, chat, do quizzes and learn.

$>$ It should be simple, funny, with added-value functionality. It should be possible to use the mobile learning system without a manual and the experience derived from usage should be interesting and engaging.

$>$ Deliver domain or area specific content just in time and place. Teachers and students should enjoy the new learning system anywhere and anytime. The system should identify the location of the user and adjust to it, be aware of data that depend on time, monitor the activities of the learner and adjust to the learner's behavior. The learner's preference should determine the behavior of the system.

To continue facilitating an improved access to education through the mobile technologies, Valk et al. (2010) advised that system and content designers should look at technical difficulties concerning quality of software and hardware, unfamiliarity with advanced smartphones and adequate teacher training on the use of mobile technology. However, Norris and Soloway (2010) have predicted, "over the next five years, Internet connected mobile computing devices will drop dramatically in price and increase in functionality" (p. 51). Hence, Park (2011) believes that with improvement in mobile device products, advanced functions, and increased applications and accessories, the technical limitations of the mobile technologies will not be the major issue in the near future. According to Park, the pressing issue will be "lack of a solid theoretical framework which can guide effective instructional design and evaluate the quality of programs that rely significantly on mobile technologies" (p.83).

To overcome the potential limitations, there should be a specific framework to support the design of mobile learning. Such a conceptual framework for mobile learning should account for the mobility of learners, cover both formal and informal learning, theorize learning as a constructive and social process, and analyze learning as a personal and situated activity mediated by technology (Sharples, Taylor, \& Vavoula, 2005). Since cost is a major factor to effective implementation of the mobile learning, all institutions planning to use the tools of the mobile technology must strike a balance in providing increased and effective education that will be affordable to both students and institutions (Valk et al., 2010).

This paper draws a roadmap and sets the ball rolling for designers of mobile learning modules, instructors and researchers in the field of education to work in situating learning with mobile technology as a method of choice in the learning environment. It also demonstrates to learners the much functionality their mobile devices offer them in attaining their educational goals. 


\subsection{Implications for m-learning in Africa}

It is worth noting that most of the studies mentioned in this paper that recorded successes experimenting with the mobile technologies have special bearing to developed countries or those regions that enjoy greater access to broadband Internet connectivity. One of the studies that explored developing countries could not support the assertion that mobile-phone-facilitated learning has a potential impact on educational outcome or promote new learning (Valk et al., 2010). I attribute this to a number of factors, among which are lack of Internet penetration due to limited broadband network and high cost of mobile devices in the developing countries. However, as the Internet penetrates further into these countries, indications are that mobile technology will be a great treasure for education, especially in Africa. This can be validated by the recent studies of Pimmer et al. (2014) who found, contrary to Valk et al. (2010) that mobile phones are capable of enhancing learning in rural and low-income areas. This could be ascribed to the escalating access to mobile devices. An unprecedented number of people own wireless handheld devices in the developing countries of Africa, and the mobile technologies offer some features that do not require Internet services, such as SMS.

Despite the expansion in access to mobile devices, however, low Internet bandwidth continues to militate against progress, leading to slow connectivity and slow response time, which may result in frustration and subsequent interference with the learning process. Out of the $63.5 \%$ mobile subscribers in Africa, only $16.3 \%$ of individuals use the Internet. Even as Africa records the highest growth rate in mobile-broadband subscription and the increased penetration from $2 \%$ in 2010 to $11 \%$ in 2013, one huge setback is the cost. Among other regions of the world, Africa remains the most expensive in mobile broadband; hence, mobile service is largely unaffordable (ITU, 2013). Considering this situation, offline access to learning materials on mobile devices should be seriously contemplated for m-learning in Africa. There is need for further research in the developing world of Africa to measure the outcome of offline mobile learning and its effects on cost reduction. This may describe best ways that mobile technology will not only increase access to education, but also decrease the cost of education.

Other areas of concern that need attention are security and privacy. Pimmer et al. (2014) observed in the South African study that the nurses had some restrictions in the use of mobile devices and social media. In some instances, they were banned from using these devices. This was largely due to challenges that relate to safe practice and privacy concerns, especially of their patients. Security and privacy concerns are global issues. Numerous steps have been taken through research in advanced countries to deal with these concerns. Similar studies need to be replicated in Africa to determine the level of awareness of users of mobile devices concerning matters of privacy. Users of mobile devices for learning purposes have to learn to draw a line between professionalism and personal use. A student nurse, for example, must not use a camera phone to take photos of a patient for learning purposes without the consent of the patient, as Pimmer et al. seemed to observe.

The few studies found on m-learning in Africa mostly conducted interviews. Only a few carried out actual experiments with mobile devices. Researchers on mobile learning in Africa should examine the design principles to be adapted in the context of the prospects and problems of their settings. In carrying out such studies, both informational and instructional materials should be provided to learners to practically engage with the technologies. This will establish a clearer picture of the situation rather than conducting mere interviews without practical exploration of the mobile devices to be used for learning.

Lack of technical skills to deal with the frequent changes in technology is a factor to look at in m-learning research in Africa. Studies on the uses of the different mobile devices among students at different levels in Africa are lacking. Users in Africa need to be studied using different variables such as age, geographical location, educational level and background, in order to identify the technical difficulties particular users face with different aspects of the mobile devices before a decision is made on the usefulness of any m-learning method for particular types of learners. 
For m-learning to be successful in Africa, teachers and educators have to be conversant with the new technologies that enhance learning. The level of technical competencies of teachers in Africa on the use of mobile technologies needs further attention. There are no substantial studies of teachers as collaborators in m-learning in Africa. Competencies of teachers and educators need to be measured to identify those areas where they need literacy training on the use of mobile technologies. There is a need for more research in Africa to develop theoretical frameworks that will evaluate programs, learners and instructors for building effective instructional design using the mobile technologies.

\section{Conclusion}

It is difficult to keep abreast with the rapid changes in technology. This calls for constant knowledge updating concerning types and uses of technologies on the side of instructors and students. The mobile technologies are not going to replace other models of electronic learning, nor will they replace the classroom. However, according to Motiwalla (2007), if used effectively, mobile technologies will add value and complement existing learning models. This paper explains how mobile technology is capable of facilitating and enhancing learning. It also provides practical ways of implementing the use of the mobile technologies to make them better suited for learning.

All technologies have their advantages and disadvantages. The drawbacks mentioned in this review must not serve as factors militating against the practical implementation of mobile technology projects in institutions of learning. This rather poses a challenge to manufacturers, content authors, content programmers and software companies to develop and provide tools with effective user interface (Butler, 2001). In this emerging trend of learning, no one is immune from acquiring basic technical knowledge of the technology devices. This places responsibility on both instructors and students. As Elias (2011) admonished, students must become familiar with the basic mobile devices with some of the complexities of the smartphones. Educators or instructors, on the other hand, must not only set their eyes on what is the next best technology tool coming, but should also focus on how to make design of instructional materials accessible using tools that are available and affordable to the students.

Acknowledgements - This paper was initially prepared and submitted by the author as a final class project for a course in Computer Education and Cognitive Science (CECS 5200) in the University of North Texas, Denton, U.S.A in fall 2011. The paper in its current form was revised and re-written by the author in 2014. Special thanks to Dr. Lisa Heinrich, Professor of Mass Communications, St. Cloud State University, Minnesota, U.S.A who proofread the manuscript.

\section{References:}

Alamaki, H., \& Seppala, P. (2002). Experimenting with mobile learning in a university environment. In World Conference on E-Learning in Corporate, Government, Healthcare, and Higher Education, 2002(1), 67-74.

Aubusson, P., Schuck, S., \& Burden, K. (2009). Mobile learning for teacher professional learning: Benefits, obstacles and issues. ALT-J: Research in Learning Technology, 17(3), 233-247. http://dx.doi.org/10.1080/09687760903247641

Brown, T. H. (2005). Towards a model for m-learning in Africa. International Journal on E-learning, 4(3), 299-315.

Butler, M. H. (2001). Current technologies for device independence. Bristol: HP Laboratories. Retrieved October 10, 2011, from http://www.hpl.hp.com/techreports/2001/HPL-2001-83.pdf

Chambo, F. F., Laizer, L. S., Nkansah-Gyekye, Y., \& Ndume, V. (2013). Mobile learning model for Tanzania secondary schools: Case study of Kilimanjaro region. Journal of Emerging Trends in Computing and 
Information Sciences, 4(9), 698-701.

Chang, A. Y., Ghose, S., Littman-Quinn, R., Anolik, R. B., Kyer, A., Mazhani, L., \& Kovarik, C. L. (2012). Use of mobile learning by resident physicians in Botswana. Telemedicine and e-Health, 18(1), 11-13.

Clay, C. A. (2011). Exploring the use of mobile technologies for the acquisition of clinical skills. Nurse Education Today, 31(6), 582-586. http://dx.doi.org/10.1016/j.nedt.2010.10.011

Cobcroft, R. S., Towers, S., Smith, J., \& Bruns, A. (2006). Mobile learning in review: Opportunities and challenges for learners, teachers, and institutions. Proceedings Online Learning and Teaching (OLT) Conference, 21-30. Brisbane: Queensland University of Technology. Retrieved September 29, 2011, from http://eprints.qut.edu.au/5399/1/5399.pdf

Conde, M. Á., García-Peñalvo, F. J., Alier, M., \& Piguillem, J. (2013). The implementation, deployment and evaluation of a mobile personal learning environment. Journal of Universal Computer Science, 19(7), 854-872.

Coulby, C., Hennessey, S., Davies, N., \& Fuller, R. (2011). The use of mobile technology for work-based assessment: The student experience. British Journal of Educational Technology, 42(2), 251-265. http://dx.doi.org/10.1111/j.1467-8535.2009.01022.x

Crompton, H. (2014). A diachronic overview of technology contributing to mobile learning: A shift towards student-centered pedagogies. In M. Ally \& A. Tsinakos (Eds.), Increasing access through mobile learning (pp 7-15). Canada: Athabasca University. Retrieved May 10, 2014, from http://www.col.org/PublicationDocuments/pub_Mobile\%20Learning_web.pdf

De Castro, M. G. A. (2014). Educational projects based on mobile learning. TESI, 15(1), 10-19. Retrieved April 30, 2014, from http://rca.usal.es/index.php/revistatesi/article/viewFile/11650/12065

Economides, A. A., \& Nikolaou, N. (2008). Evaluation of handheld devices for mobile learning. International Journal of Engineering Education, 24(1), 3-13.

Elias, T. (2011). 71. Universal instructional design principles for mobile learning. International Review of Research in Open \& Distance Learning, 12(2), 143-156.

Fisher, M., \& Baird, D. E. (2007). Making mLearning work: Utilizing mobile technology for active exploration, collaboration, assessment, and reflection in higher education. Journal of Educational Technology Systems, 35(1), 3-30. http://dx.doi.org/10.2190/4T10-RX04-113N-8858

Gay, G., Rieger, R., \& Bennington, T. (2002). Using mobile computing to enhance field study. In T. Koschmann, R. Hall \& N. Miyake (Eds.), CSCL2: Carrying forward the conversation (pp. 507-528). Mahwah, NJ: Lawrence Erlbaum Associates.

Gibbons, C. (2009, July 16-17). How does having a pocket PC affect doctoral students' experience of learning? A case-study and its implications for postgraduate research training. Paper presented at the 4th International Conference on E-Learning, University of Toronto, Canada. Retrieved November 12, 2011, from

http://www.nottingham.ac.uk/visuallearninglab/documents/reportfiles/gibbons\%20cathy\%20final\%20p aper.pdf

Global Mobile Statistics. (2014). Mobile subscribers worldwide. Retrieved May 11, 2014, from http://mobithinking.com/mobile-marketing-tools/latest-mobile-stats/a\#subscribers

Hwang, G., \& Tsai, C. (2011). Research trends in mobile and ubiquitous learning: A review of publications in selected journals from 2001 to 2010. British Journal of Educational Technology, 42(4), 65-70. http://dx.doi.org/10.1111/j.1467-8535.2011.01183.x

ITU. (2013). ICT facts and figures. Retrieved February 19, 2014, from http://www.itu.int/en/ITU-D/Statistics/Documents/facts/ICTFactsFigures2013-e.pdf

Johnson, A. T. (2013). Exploring the use of mobile technology in qualitative inquiry in Africa. The Qualitative Report, 18(22), 1-14.

Keegan, D. (2002). The future of learning: From elearning to mlearning. Retrieved November 15, 2011, from http://www.design4instruction.com/articles/pdf/elearning2.pdf

Kim, S. H., Mims, C., \& Holmes, K. P. (2006). An introduction to current trends and benefits of mobile wireless technology use in higher education. AACE Journal, 14(1), 77-100. 
Examining the progression of mobile technologies and their applications to learning environment

Kingston, D. G., Eastwood, W. J., Jones, P. I., Johnson, R., Marshall, S., Hannah, D. M., \& Seibert, J. (2012). Experiences of using mobile technologies and virtual field tours in physical geography: Implications for Hydrology Education. Hydrology \& Earth System Sciences, 16(5), 1281-1286. http://dx.doi.org/10.5194/hess-16-1281-2012

Lim, T., Fadzil, M., \& Mansor, N. (2011). Mobile learning via SMS at Open University Malaysia: Equitable, effective, and sustainable. International Review of Research in Open and Distance Learning, 12(2), 122-137.

Lwoga, E. (2012). Making learning and web 2.0 technologies work for higher learning institutions in Africa. Campus-Wide Information Systems, 29(2), 90-107. http://dx.doi.org/10.1108/10650741211212359

Martin, F., \& Ertzberger, J. (2013). Here and now mobile learning: An experimental study on the use of mobile technology. Computers \& Education, 68, 76-85. http://dx.doi.org/10.1016/j.compedu.2013.04.021

Marwan, M. E., Madar, A. R., \& Fuad, N. (2013). An Overview of mobile application in learning for student of Kolej Poly-Tech Mara (KPTM) by using mobile phone. Journal of Asian Scientific Research, 3(6), 527-537.

Meeker, M. (2014). Internet trends 2014-code conference. Retrieved May 28, 2014, from http://www.kpcb.com/internet-trends

Motiwalla, L. F. (2007). Mobile learning: A framework and evaluation. Computers \& Education, 49(3), 581-596. http://dx.doi.org/10.1016/j.compedu.2005.10.011

Naismith, L., Lonsdale, P., Vavoula, G., \& Sharples, M. (2004). Literature review in mobile technologies and learning. University of Birmingham: NESTA Futurelab Series. Retrieved October 24, 2011, from http://webcache.googleusercontent.com/search?q=cache:http://telearn.archives-ouvertes.fr/docs/00/19/0 1/43/PDF/Naismith_2004.pdf

Norris, C., \& Soloway, E. (2010). Why is mobile technology different from other technology? District Administration, 46(2), 51-51.

Park, Y. (2011). A pedagogical framework for mobile learning: Categorizing educational applications of mobile technologies into four types. International Review of Research in Open and Distance Learning, 12(2), 78-102.

Pegrum, M., Oakley, G., \& Faulkner, R. (2013). Schools going mobile: A study of the adoption of mobile handheld technologies in Western Australian independent schools. Australasian Journal of Educational Technology, 29(1), 66-81.

Pimmer, C., Brysiewicz, P., Linxen, S., Walters, F., Chipps, J., \& Gröhbiel, U. (2014). Informal mobile learning in nurse education and practice in remote areas-a case study from rural South Africa. Nurse Education Today. Retrieved April 25, 2014, from

http://www.christoph.pimmer.info/wp-content/uploads/2008/08/PrePrint-Pimmer-et-al-Informal-mobile -learning-in-nurse-education.pdf

Rainie, L. (2011). As learning goes mobile. Retrieved November 14, 2011, from http://www.pewinternet.org/ /media//Files/Presentations/2011/Oct/2011\%20-\%2010\%2020\%2011\%20 -\%20As\%20learning\%20goes\%20mobile\%20pdf\%20-\%20Educause.pdf

Sharples, M., Taylor, J., \& Vavoula, G. (2005). Towards a theory of mobile learning. Proceedings of mLearn 2005, 1(1), 1-9.

Shen, R., Wang, M., Gao, W., Novak, D., \& Tang, L. (2009). Mobile learning in a large blended computer science classroom: System function, pedagogies, and their impact on learning. IEEE Transactions on Education, 52(4), 538-546. http://dx.doi.org/10.1109/TE.2008.930794

Stav, J., Nielsen, K., Hansen-Nygard, G., \& Thorseth, T. (2010). Experiences obtained with integration of student response systems for iPod touch and iPhone into e-learning environments. Electronic Journal of e-Learning, 8(2), 179-190.

Trifonova, A. (2003). Mobile learning-review of the literature. Retrieved October 10, 2011, from http://eprints.biblio.unitn.it/359/1/009.pdf

Trifonova, A., \& Ronchetti, M. (2003). Where is mobile learning going? In World Conference on E-Learning in Corporate, Government, Healthcare, and Higher Education, 2003(1), 1794-1801. 
Dankasa, J.

Valk, J., Rashid, A. T., \& Elder, L. (2010). Using mobile phones to improve educational outcomes: An analysis of evidence from Asia. International Review of Research in Open and Distance Learning, 11(1), 117-140.

Winters, N. (2013). Mobile learning in the majority world: A critique of the GSMA position. The SAGE Handbook of Digital Technology Research, 402. Retrieved April 13, 2014, from http://eprints.ncrm.ac.uk/2888/1/26_Winters_SAGE_handbook.pdf

Ying, S., Lun, L. S., Zipf, P., \& Kimm, K. (2014). Design and development of a supported tiered software for teaching and learning using a connected mobile learning application. World Applied Sciences Journal, 30, 247-255. 